\title{
Smart Classroom Environment Via IoT in Basic and Secondary Education
}

\author{
Hicham EL Mrabet, Abdelaziz Ait Moussa \\ Department of Computer Sciences, Faculty of Sciences, Mohammed First University \\ Oujda, Morocco \\ hi.elmrabet@gmail.com; a_aitmoussa@yahoo.fr
}

\begin{abstract}
The rapid evolution of information and communication technologies (ICT) has created a new paradigm of the Internet, known as the Internet of Things (IoT), which represents a group of connected objects Using wireless links (WiFi, RF, NFC, Zigbee...) to exchange information between objects and persons. The Internet of Things has changed the way people and objects interact with each other, and education has not been immune to this change, which has created new forms of interaction between teachers and learners that helps improve the teaching and learning process.In the field of education, we can imagine that students use new technologies to carry out projects and educational activities in the classroom. In this research,the focus is on the application of Internet of Things in the Smart Classrooms. This paper presents and discusses the need of integrating the Internet of Things to improve learning at the basic and secondary school, mainly through information and communication technologies (ICT) at its disposal.
\end{abstract}

Keywords- Internet of Things, Smart Classroom, ICT, Flipped Classroom

\section{Introduction}

Today, several information and communication technologies (ICTs) are present throughout the world, and their use is progressing considerably in terms of education. ICTs have great power to improve the outcomes of teaching and learning. The realization of this power depends very much on how the teacher uses technology during the learning sessions, knowing thatthe education is a powerful path for social change, social mobility, it helps develop and build a new generation of our nation. In this context, smart classes play an important role in the transformation of traditional education into modern education, which offers opportunities for improving the quality of education and academic achievement, access to education and equity, through mobile devices, classes that integrates many different types of computer hardware, including computers, tablets, interactive whiteboards, smartphones, and many computer technologies that are Used for teaching purposes. When talking about intelligent classes, we must evoke the notion of the Internet of objects (IOT), which represents the universe of connected objects in all domains, such as the field of education.

The level of connectivity offered by the Internet of Things makes it possible to enrich the learning process for students all over the world, and the application of IoT in education aims to build an ecosystem where Students and teachers can gain a thorough and empirical understanding of their environments and can trigger change of learning using loT 


\section{Literature review}

Technology is among the elements that strongly influences everyday life, and currently, the Internet of Things has the power to change our world, a paradigm shift in technology that will invade many areas of our daily life.

\subsection{Internet of things}

The Internet of Things represents a network that enables digital identities and physical objects to be identified directly via standardized electronic identification systems and wireless devices (WSN, NFC, Zigbee, RF...), and thus to be able to retrieve, store, transfer and process discontinuity between physical and virtual worlds. The Internet of Things has the power to change our world, a paradigm shift in technology that will invade multiple domains, and the following figure outlines the most useful areas for IoT.

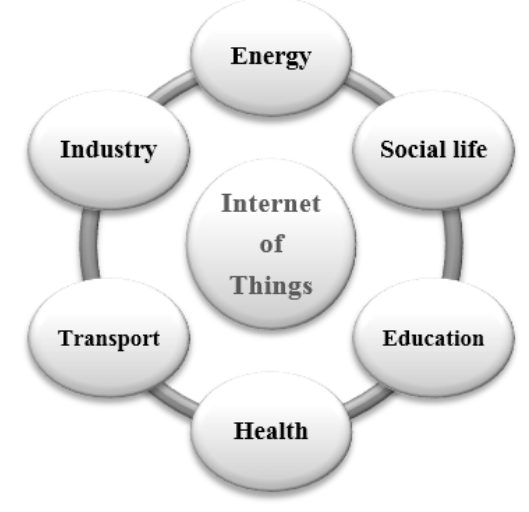

\subsection{Internet of things in education}

The education system offers permanent opportunities for intelligent learning, content, pedagogy or values to convey. Generally, it is asserted that pedagogy is the way to transfer knowledge between the teacher and the learners. At all times, the teacher must update his knowledge transfer methods and techniques.

The integration of loT gives the learner the possibility of being also the mediator of knowledge in order to reinvest in the class the knowledge and the strategies acquired outside the class and that the teacher is definitely the more the only mediator of knowledge, he will feel valued and will be more motivated.

\section{Proposed Work}

In this section, we present related work, which focuses on the smart classroom environment. Through this study, it should show how we can improve the learning process based on related educational approaches.we propose new learning approach, knowing that the evolution of the research is mainly motivated by the taking into account of the new technologies of loT in parallel to the teaching pedagogical approaches.

\subsection{The structure of smart learning process via IoT}

Integration of IoT as a new actor in intelligent learning can facilitate the interaction between people (learners and teachers) and objects (Devices, RFID Tag ...) in the school environment. This interaction 
means that objects can communicate with each other and with people who are in these educational environments.

Smart learning process lets learner complete their coursework on their mobile devices (Tablets, Smartphones,Laptop, connected objects...) and learners have complete access to their real-time class and collaborative learning from their mobile device.

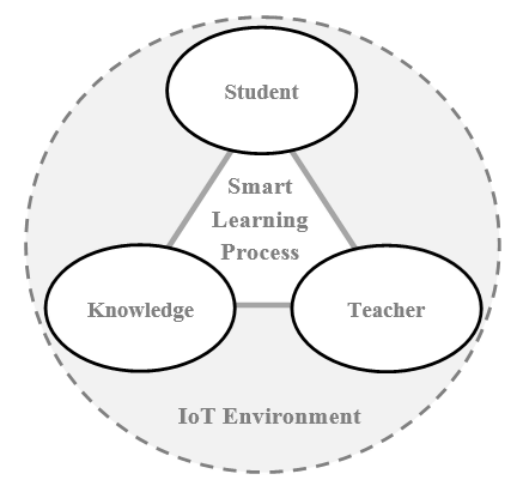

Figure 1 loT in Smart learning

The structure of smartlearning and a management system include the following aspects:

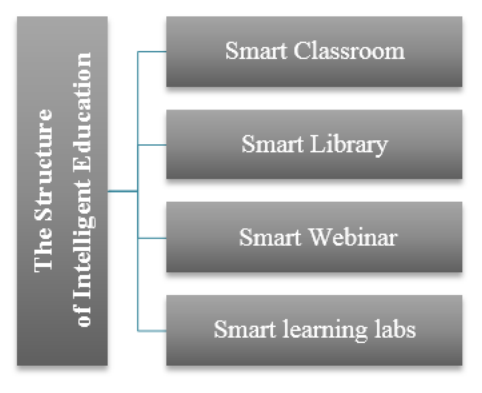

\subsection{The IoT-Learning approach}

Our loT-Learning approach based on connected objects in basic and secondary school, is represented by a pedagogical triangle, modified and surrounded by a sphere representing the universe of loT.The loTLearning model can be represented by the following diagram

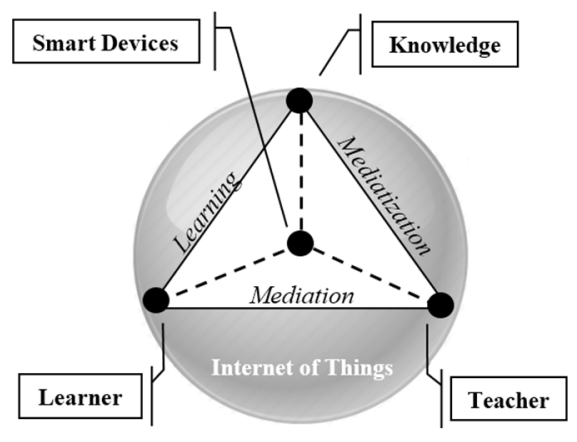

Figure 2. The IoT-Learning approach

In our model the 'Devices' pole of the classic triangleis replaced by 'Smart Devices'. This is due to the logic of the fact that the pedagogical situation using ICT is essentially based on access to information. The 
teacher plays a dual role. It governs, on the one hand, the process of mediation, by which it ensures the pedagogical relationship in order to facilitate the acquisition of knowledge by the learner. It then fulfills a pedagogical function of management, interactive regulation of learning events. On the other hand, it assumes the process of medialization, by which it is responsible for transforming a part of collective knowledge into useful information for learning.In this sense, books, digital textbooks, posters and interactive boards, as well as the training system, the virtual campus, etc., appear as the result of the medialization process.

By adopting the power of ICT and the Internet of things in educational practice, learners benefit in many ways. Technology helps them to approach all learning styles, participate interactively and sharing, making learning personal, dynamic, collaborative and up to date. In addition, learning goes beyond class. Interacting with so many everyday objects connected to the Web, students have access to unlimited course from anywhere, and anytime. The smart class system identifies each student already integrated into each student ID card. The system is expected to use loT node transceivers, making it perfect for indoor location.

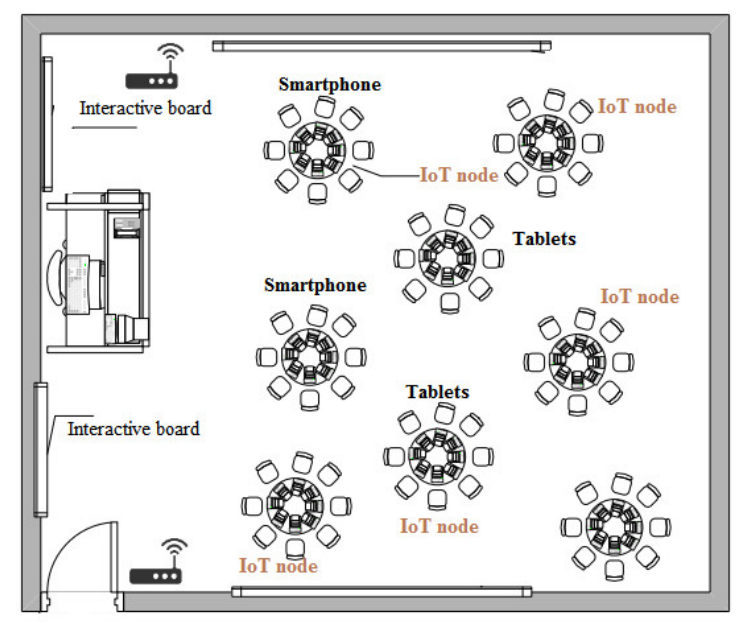

Figure 2. Architecture of the future classroom

In this case study,oursmart classroom for basic and secondary school, students will implement in all classes of the school and aims to solve the full participation rate of entire students at any period.The loT technology integrated into the classroom is a special classroom with a precise purpose and mission can provide students with alternative methods and choices.

Research in the teaching / IOT discipline should address these three factors:

- $\quad$ Confidentiality

- The availability of data

- $\quad$ Pedagogical approaches to teaching

\section{Discussion and Future Works}

We presented a new framework for recommending new pedagogical approaches for integrating loT into smart classesand the concept of collaborative learning via loT. Besides, the proposed approach loTLearning cover other important dimensions, such as the impact of the loT environment on the learners' level of knowledge and cognitive load.Future work aims to develop an intelligent environment based on an loT authentication system that allows learners to identify themselves in intelligent classes 
This global analysis blends the opinions of those who have experienced the use of connected objects in class with those who have never done so. Also, there is the risk of confusing proven benefits with hopes of profits.

The overall responses of the 100 teachers are illustrated in the following graph.

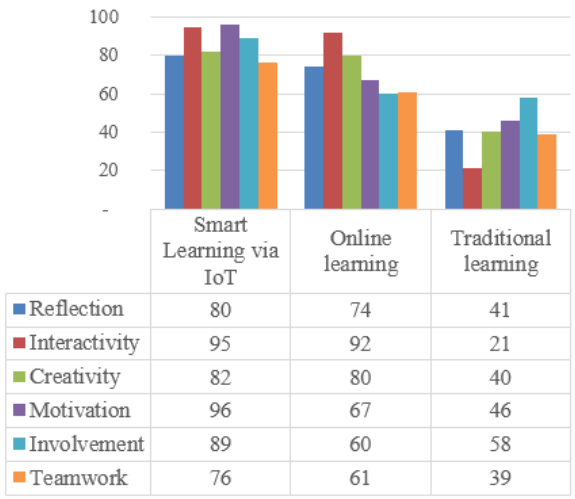

Figure 3. Comparison of different types of learning

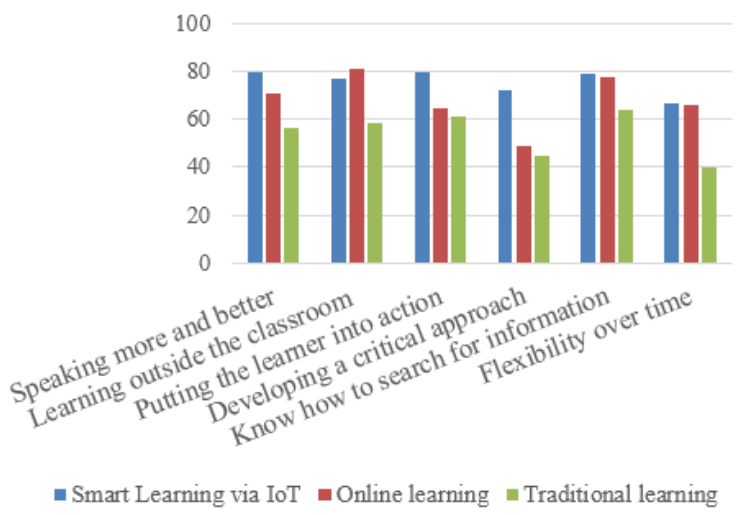

Figure 4. Advantge of Smart learning via loT

To conclude this section, it should be noted that the overall score for observing the benefits of connected objects is significantly influenced by seniority in the career. The youngest in the teaching profession have a much more positive opinion than those who have older.

\section{Conclusions}

Nowadays, loT is a smart network that connects all things to the Internet for exchanging information and communicating through exchange information and communicate through intelligent objects. There are enormous values in the adaptation of IoT throughout the education system. IoT enables the education system to be more relevant and effective. In the future, most educational institutions will gradually use loT technologies to improve the learning process, and distance education. The new digital culture will create virtual schools that rely on Internet objects to encourage off-campus learning and expand participation in modern learning. 


\section{REFERENCES}

[1] B. Jonathan, and A. Sams, "Flip your classroom: Reach every student in every class every day," in International Society for Technology in Education, 2012.

[2] Jeannette Chinand Vic Callaghan, “Educational Living Labs: A Novel Internet-ofThings Based Approach to Teaching andResearch" , 9th IEEE International Conference on Intelligent Environments, Athens, Greece, 16 - 19 July 2013.

[3] S. Kim, S.-M. Song, and Y.-I. Yoon, "Smart learning services based on smart cloud computing," Sensors, vol. 11, no. 8, pp. 7835-7850, 2011.

[4] T. Kim, J. Y. Cho, and B. G. Lee, "Evolution to smart learning in public education: a case study of Korean public education," Open and Social Technologies for Networked Learning, vol. 395, pp. 170-178, 2013.

[5] Ma Guojun, Li Yueguang, "Application of IOT in Information Teaching of Ethnic Colleges",International Conference on Information, Business and Education Technology (ICIBIT 2013).

[6] J. Valk, A.T. Rashid and L. Elder, "Using mobile phones to improve educational outcomes: An analysis of evidence from Asia",The International Review of Research in Open and Distance Learning, vol. 11, pp. 117-140, 2010.

[7] M. Saylor, "Active Learning and Virtual Worlds," The mobile wave: how mobile intelligence will change everything, Vanguard Press. pp. 176-180, Jan. 2013.

[8] J.S. Sung, "Design of Smart Learning in Mobile Environment." IJSEIA, vol. 9, no. 12, pp. 373-380, Dec. 2015.

[9] Z.-T. Zhu, M.-H. Yu, P. Riezebos, "A research framework of smart education". Smart Learn. Environ. 3(1), 1-17 (2016)

[10] Kim, S. (2008). Étude des représentations du personnel enseignant à l'égard de ses pratiques d'ordre technologique et pédagogique actuelles et de celles qui pourraient favoriser la mise en œuvre d'un dispositif de formation à distance à l'Institut de Technologie du Cambo. Université de Sherbrooke. 